\title{
Primeiro Seminário Latino-Americano de Bibliografia
}

DeL 21 del presente mês de noviembro al 4 de diciembre próximo se efectuará en esta ciudad de México el Primer Seminario Latino-americano de Bibliografia, Documentación y Canje de Publicaciones, bajo los auspicios de la Secretaria de Educación Pública y la Organización de las Naciones Unidas para la Educación, la Ciencia y la Cultura (UNESCO). El seminario tendrá lugar en los locales del Centro de Documentación científica y Técnica de México, institución nacida de un contrato celebrado en noviembre de 1950 entre la Secretaria de Educación Pública y el Departamento de Assistência Técnica de la UNESCO. Así, pues, la próxima reunión viene a constituir el acontecimiento de mayor relieve en la conmemoración del décimo aniversário de dicho Centro.

Al seminario asistirán delegados de todos los países del Continente Amerciano, así como un gran número de observadores, tanto latino-americanos como europeos y asiáticos. Al efecto, el Dr. Vittorino Veronese, Director General de la UNESCO, ya envió las invitaciones oficiales a todos los países miembros de êste organismo especializado de las Naciones Unidas, con objeto de lograr un intercâmbio de opiniones y experiencias entre los especialistas de dichas matérias de todo el mundo.

En esta oportunidad se discutirán, de preferência, los problemas relativos a la bibliografia centro-americana, con miras a hacerla extensiva a tôda la América Latina y convertirla, portanto, en latino-americana. Asimismo, se discutirán los problemas de la documentación en Latino-america y se buscarán los sistemas adecuados para mantener informados, oportuna y adecuadamente, a los intelectuales de los países de la región.

la distribución e intercâmbio de publicaciones entre los países latinoamericanos

Otro de los importantes temas que se someterán a discusión será el de la distribucion e intercanbio de publicaciones entre los paises latino-americanos $y$, en general, los de todo el mundo, a fin de encontrar los medios que den a conocer mejor la contribución bibliográfica latino-americana.

Desde 1957, en que tuvo lugar en Panamá el Segundo Seminario Bibliográfico de Centro-américa y el Caribe, organizado por la UNESCO en cooperación con la Biblioteca Nacional y el Grupo Bibliográfico de dicho país, México se interesó en que suas especialistas en la matéria tuvieran la oportunidad de discutir sus problemas y conocer la experiência de sus colegas de otros países, habiendo invitado a la UNSCO para que la siguiente reunión, de alcance continental, tuviera como sede la capital mexicana, lo que fue aceptado inmediatamente por êste organismo especializado de las Naciones Unidas. 
UN PROBLEMA DIRECTAMENTE RELACIONADO CON EL PROGRESSO DE LA CIÊNCIA

En el mundo se está agudizando cada dia más un problema de gran transcendência, ya que está directamente relacionado con el progresso de la ciência. Según cálculos conservadores, existen en la actualidad un millón de hombres de ciência, aproximadamente, pero el número de ellos - que, según opiniones autorizadas, «tienen en sus manos, en gran parte, el destino de la Humanidad» - llegará a la pasmosa cifra de veint ea treinta millones al finalizar êste siglo. La casi totalidad de estos trabajadores intelectuales está contdibuyendo en forma permanente al progresso de la ciência.

Lá bibliografía técnica mundial constituye una riqueza de información que es el resultado del registro de las experiencias y los éxitos técnicos de esos trabajadores. Esta información, a su vez, constituye una muy importante fuente de riqueza nacional.

Durantelos últimos años, el volumen de la contribución bibliográfica ha ido aumentando en tales proporciones, que su control resulta casi imposible. Por lo demás, el problema se va agudizando de tal manera, que algún especialista ha afirmado que es más económico repetir una investigación que cueste menos de cien mil dólares, que averiguar si ha sido registrada antes en la bibliografía mundial.

En estos problemas están interesados todos los países, tanto los de gran desarrollo técnico e industrial como los todavia poco desarrollados. En la América Latina, esta preocupación la comparten no sólo los investigadores científicos, sino también los bibliógrafos interesados en los sistemas modernos de información especializada.

Como antecedentes destacados de la reunión que ahora se celebrará en México son de mencionarces la Conferência sôbre Información Científica organizado por la Sociedad Real de Londres, en 1948, y la Conferência Internacional sôbre Información Científica llevada al cabo por la Academia Nacional de Ciências de los Estados Unidos de América, en 1958». 